\title{
Sustainable Development Index in Hong Kong: Approach, Method and Findings
}

\author{
Geoffrey K. F. Tso $\cdot$ Kelvin K. W. Yau • C. Y. Yang
}

Accepted: 3 May 2010/Published online: 12 May 2010

(C) Springer Science+Business Media B.V. 2010

\begin{abstract}
Sustainable development is a priority area of research in many countries and regions nowadays. This paper illustrates how a multi-stakeholders engagement process can be applied to identify and prioritize the local community's concerns and issues regarding sustainable development in Hong Kong. Ten priority areas covering a wide range of community's concerns in relation to the economic growth, societal development and environmental protection have been identified. An index is then constructed based on these priority areas to track the public's views on the progress of Hong Kong towards a more sustainable city.
\end{abstract}

Keywords Economic growth - Environmental protection - Societal development · Sustainable development

\section{Introduction}

According to the Brundtland Report (World Commission on Environment and Development 1987), sustainable development is known as Our Common Future. It is the capacity to satisfy the needs of the present generation without jeopardizing the possibility of doing so for future generations. Recently sustainable development of a country or a region has received more and more attention. In particular, Hoballah (2006) summarized the important factors and his successful experience in formulating a regional strategy for the sustainable development in the Mediterranean region. Munday and Roberts (2006) examined a list of approaches that have been considered in Wales in order to monitor and measure the progress towards sustainable development objectives, including the ecological footprint, the index of sustainable economic welfare, the environmental satellite account, and environmental input-output tables. Roberts (2006) reviewed some of the fundamental

G. K. F. Tso $(\bowtie) \cdot$ K. K. W. Yau · C. Y. Yang

Department of Management Sciences, City University of Hong Kong, Kowloon, Hong Kong e-mail: msgtso@cityu.edu.hk

C. Y. Yang

Department of Statistics, Yunnan University, Kunming, People's Republic of China 
requirements for the evaluation of regional sustainable development and provided research evidence that indicated the need for procedural and institutional innovation. While many studies have been conducted in the Western countries, there was a lack of measures relating to quality of life in different Chinese contexts. Shek (2010) pointed out that the predominance of studies based on non-Chinese participants has limited our understanding of the related phenomena in the Chinese culture. The present study contributes to the literature in associating quality of life with sustainable development in a Chinese population. Lu and Lo (2007) analyzed the economic-environmental performance for some regions in China in order to make a reasonable policy based on its ability to maximize wealth as well as to minimize the environmental impacts for its inhabitants. In particular, integration between cross-efficiency measure and cluster analysis was applied to construct a benchmark-learning roadmap for those inefficient regions to improve their efficiency progressively. Luken and Hesp (2007) assessed the impact of industrial development and environmental policies on sustainable development of six developing countries by referring to a set of economic, social and environmental parameters. Zavadskas et al. (2007) developed a model for rational sustainable development in Vilnius with a special emphasis on the effect of pollution. It involved a complex analysis of micro, meso, and macro environmental factors that may affect Vilnius' sustainability, together with recommendations for enhancing sustainable development. Kizilaslan et al. (2007) evaluated the sustainable development of Turkey in aspects of population growth, economic development, deforestation rate, size of the forests, population density, agricultural development, selfsufficiency rate and urban population. $\mathrm{Ng}$ (2007) outlined the contextual background for understanding sustainable development and governance issues in Asian cities. Short (2008) investigated the methodologies and policies for promoting and ensuring sustainable industrial development in Rwanda. The Government's role in providing an appropriate supporting frame was also examined.

When comparisons of sustainable development among countries or regions are made, multidimensional variables, such as economic, environmental and social variables, should be considered. To have an objective indication and comparison, a sustainable development index (SDI) is needed. There are different ways of measuring sustainable development which basically depends on the specified objectives of the study. One approach is to construct a SDI based on official statistics to provide an objective measure. This approach, however, cannot reflect directly the opinions and feelings of the people living in the study region. Another approach is by conducting a survey; this alternative can measure the views from different sub-group population and produces indicators that can compare the sentiments amongst the sub-group population. Pioneer works on the construction of SDI have been carried out by Nordhaus and Tobin (1973), Daly and Cobb (1989) and in the recent survey by Lawn (2003). The roots index was developed by Hoffman (2000) as a measure of local sustainable development in New York City (1990-1995), which focused on the foundations of sustainable economic activities and factors that had long-term impacts such as infrastructure and education. In Hong Kong, a Social Development Index has been developed by the Hong Kong Council of Social Services. Corresponding reports are published bi-annually since 2000. The index consists of 47 core indicators involving 14 different sectors and 5 disadvantaged population groups. Details of the construction of the index can be found in Chua et al. (2010). A regional-scale SDI was developed by HerreraUlloa et al. (2003) for Baja California Sur of Mexico, taking into consideration the social, environmental, economic and institutional dimensions. Using the principle component analysis (PCA), an index for sustainable development was developed by Tarabusi and Palazzi (2004), which structurally took into account the balance of the various 
development aspects and thereby weighed any unbalance negatively. To develop this index, economic, environmental and social aspects of the development of a country were considered. As an application, the sustainable development of 126 countries in the world were compared and ranked by using this index. The concept of sustainability they adopted was a 'sustainable society', which introduced in the measurement the corresponding features in order to develop and maintain the stability of the society. Ledoux et al. (2005) presented an overview of a set of sustainable development indicators recently adopted by the European Commission to monitor, assess and revise the sustainable development strategy adopted in Gothenburg in 2001. Furthermore, some approaches to the construction of a SDI for the Philippines were proposed by Barrios and Komoto (2006), in which sparse principle component analysis (SPCA) was used instead of PCA to facilitate interpretation of results. In their study, SDI was also used to indicate the areas in which improvement was required so as to achieve a better and sustainable quality of life.

Hong Kong, as a special administrative region of China after 1997, has an increased awareness of the need for continuous growth and sustainable development. Chiu (2000) preliminarily assessed the overall environmental sustainability of the existing housing system of Hong Kong and the usefulness of Bhatti's building life-cycle model in developing a policy for sustainable housing development. Chiu (2002) applied the sustainable development perspective to investigate whether policy changes and government responses to the collapse in the property market have made the distribution and consumption of the resources in Hong Kong more equitable. Robert and Hills (2002) discussed the sustainable development of Hong Kong and Scotland by considering the impact of changing circumstances. Hills (2002) discussed the recent evolution of environmental policy in Hong Kong, the emergence of a regional environmental management agenda and the potential of ecological modernization as a basis for the development of a broader strategy to manage the environmental problems of the Pearl River Delta Region. Lai et al. (2006)discussed a Coasian interpretation of a model of sustainable development for Hong Kong that incorporated economic, societal and environmental factors.

However, when it comes to putting sustainable development into practice, it is sometimes difficult to figure out the areas of major concern. The development and construction of the Hong Kong Sustainable Development Index (HKSDI) adopts a systematic approach to collect information from multi-stakeholders in order to determine the most important areas to be addressed for sustainable development. It not only serves as a tracking mechanism on the state of affairs, but also takes up the role as a device for consensus building and a useful tool in raising public awareness. This paper describes the development of the HKSDI and presents its findings from year 2003 to 2007. Top priority areas are identified and quantified. It provides a useful frame of reference for the businesses, government and civil society to collaborate in addressing common sustainability challenges and meeting the aspirations of the citizens.

\section{Determining Priority Areas of Sustainable Development}

In Hong Kong, the Chief Executive stated in his Policy Address (1999) an endeavour to building Hong Kong into a world-class city. Making Hong Kong a clean, comfortable and pleasant home requires a fundamental change of mindset. Every citizen, business, Government Department and Bureau needs to start working in partnership to achieve sustainable development. In simple terms, sustainable development for Hong Kong means: 
i. finding ways to increase prosperity and improve the quality of life while reducing overall pollution and waste;

ii. meeting our own needs and aspirations without doing damage to the prospects of future generations; and

iii. reducing the environmental burden we put on our neighbours and helping to preserve common resources.

While progress has been made in raising public awareness of sustainable development, the fundamental change of mindset, has yet to occur. The Government formed the Sustainable Development Council in April 2003 to lead the development of sustainable development strategies in Hong Kong. The Council has developed strategies for addressing the specific issues of waste management, urban planning and renewable energy, with new strategies for population policy and air quality through public consultation.

These are positive steps but what is needed is a holistic strategy to address the diverse yet interconnected issues that will further enhance the sustainability of Hong Kong, not a set of strategies on individual topics. To get a clearer picture of areas to-be-improved, however, we need an effective way to measure Hong Kong's quality of life. Sustainable development indicators can influence behaviour, assist in the design and implementation of improvement programs, and enable progress to be monitored. Continuing to develop good policy requires a clear and holistic road map to improve its quality of life, including measurable indicators and targets. For this reason, the HKSDI has been designed and launched in 2003 based on the 10 priority areas that represent a wide range of community concerns in relation to the local economy, social progress and the environment. These 10 areas were identified through multi-stakeholder engagement workshops conducted in 2001 and 2002 to identify priority areas for Hong Kong's sustainable development. Thus, this index can reflect a wide range of economic, social and environmental issues that are relevant to Hong Kong and tracks the public's view on Hong Kong's progress towards a more sustainable future.

The first workshop conducted in 2001 involved over 70 participants interested in the topic, including government officials, business operators, environmental consultants and members from various chambers of commerce. During the workshop, particular questions like "what are your priorities for a sustainable society in Hong Kong?" and "how would you define them and what targets should Hong Kong achieve?" etc. were used to focus discussions on three topic areas of social, economic and environmental sustainability. As a result, participants reached consensus, through interactive, facilitated discussions, on a list of over 30 priority issues important to Hong Kong's sustainable development.

The second workshop, which was part of the Government's International Symposium on Sustainable Development, reviewed the identified priority issues and reached consensus on the top ten priorities for sustainable development in Hong Kong through debates. The second workshop involved a diverse group of stakeholders who represent a variety of sectors including business, government, environmental and social organizations, academics and professionals. The goal of the workshop was to identify top ten priorities that participants believe should be the focus of action to further sustainable development in Hong Kong. An interactive consensus building process was used to reach the conclusion of the top ten priority areas. During the process, the workshop participants were divided into 10 small discussion groups, each comprising up to 10 members from different stakeholder groups and being led by an independent facilitator. Each small group then reviewed and discussed according to the following outlines: 
1. Individuals in each group first reviewed the priorities from the previous workshop, considering the local and international context of Hong Kong's sustainability; they then selected their top five priorities.

2. Each member then shared their top five priorities with the group while the facilitator counted the votes of each priority.

3. Each group discussed the selected priorities in order to understand each other's views and to see whether there was an agreement on the group's selection of top ten priorities.

4. After discussing their rationales for why a priority should be on the list or not, each group member was then asked individually to identify the top ten priorities that he/she believed should be on the list.

5. These results were shared within each group and, however, if an effective consensus was not attained on the list of top 10 priorities, the "fist five" tool $^{1}$ was employed to show members' support for including or excluding particular priorities.

After reaching a consensus on the list of top ten priorities in each small group, all participants re-convened to share their results and to discuss ways forward to reach a consensus as a larger group on the final list of top ten priorities. As a result, criteria were suggested to filter the priorities, and a list of top ten priorities emerged. The "fist five" technique was used again to gauge the level of support for the final list among the participants.

At the end of the second workshop, the following ten areas were determined to be the priority areas for sustainable development in Hong Kong, including: caring and ethical employers, Civil Liberties and Human Rights, community spirit and well-being, educational system, environmental protection, health and hygiene, Healthy Economy, Integration with the Mainland, population policy, and urban planning.

As a remark, the current method of determining priority areas of sustainable development may be criticized as subjective. However, given the resource limitations and other constraints, to conduct a large scale opinion poll to determine the priority areas is infeasible. The current way to determine the priority areas is an attempt to strike for a balance, with an aim to systematically collect information from multi-stakeholders, which is assumed to be representative for the population's view.

\section{Construction of HKSDI}

The HKSDI was developed as an indicator to reflect changes in public opinion regarding sustainable development in Hong Kong. Annually between July and September over 2,000 randomly sampled Hong Kong residents, aged 18 or above, were surveyed by telephone. Respondents were engaged in detailed conversations, usually lasting for 20-30 min, about issues that were critical to the sustainability of Hong Kong.

For each priority area, respondents were asked to indicate their ratings, using a 10-point scale, regarding the following attributes:

\footnotetext{
1 "Fist five" is a consensus-building tool that enables group members to indicate the extent to which they support a decision, e.g. five fingers indicates unwavering support and a fist indicates absolute disagreement with the way forward. Depending on the number of fingers shown, from none to five, the group can effectively gauge the level of support for an outcome and then discuss it until the group agrees on or accepts the outcome or decision.
} 
1. How important the priority area is for achieving and sustaining quality of life in Hong Kong?

2. Which aspect(s) of the priority area are important for improving quality of life in Hong Kong?

3. How satisfied he/she is in regard to Hong Kong's performance in the priority area?

\subsection{Calculating the Index}

The HKSDI is defined by a weighted average of satisfaction scores of the ten pre-specified priority areas. It has a range between 0 and 100. The relative levels of importance of the 10 priority areas were used as weights. The importance levels of the 10 priority areas were first normalized into a percentage distribution, so as to produce a summed total of one.

In particular, the computational formula of HKSDI is given by

$$
\begin{gathered}
\text { HKSDI }=\frac{\sum_{i=1}^{10} \overline{W_{i 1}} \overline{P_{i 1}}}{\sum_{i=1}^{10} \overline{W_{i 0}} \overline{P_{i 0}}} \times 100 \\
\overline{W_{i}}=\frac{1}{n} \sum_{j=1}^{n} W_{i j} \\
\overline{P_{i}}=\frac{1}{n} \sum_{j=1}^{n} P_{i j}
\end{gathered}
$$

where

$W_{i j}$ is the level of importance for priority area $i$ provided by respondent $j$;

$P_{i j}$ is the satisfaction level for priority area $i$ provided by respondent $j$;

$n$ is the sample size.

$\overline{W_{i 1}}$ and $\overline{P_{i 1}}$ are the average importance level and satisfaction level respectively for priority area $i$ of the current year;

$\overline{W_{i 0}}$ and $\overline{P_{i 0}}$ are the average importance level and satisfaction level, respectively for priority area $i$ of the base year 2003 .

The specific objectives of the index are:

1. To assess the importance of sustainable development priority areas within the Hong Kong community;

2. To determine what sustainable development priority areas mean to the community;

3. To track community perceptions on the importance of sustainable development priority areas and the progress in managing these areas; and

4. To raise awareness of the important role of the priority areas in furthering sustainable development.

\section{Key Findings}

Each year an aggregated score is calculated based on the results of the survey that provides an annual measure of progress in furthering sustainable development in Hong Kong. 
In 2007, the overall Index score was 103.7, slightly higher than 102.2 in 2006. Statistically, the index values in 2004, 2005 and 2006 do not significantly deviate from each other. In 2005 it was 102.5 and in 2004 it was 102.8 . The baseline measure of 2003 was 100 . This modest annual increase in the Index from the baseline year indicates that Hong Kong people perceived some progress has been made in addressing the priority areas of the Index since 2003. The following table shows the HKSDI values from 2003 to 2007 (Table 1).

\subsection{How Important is Each Area in Achieving Quality of Life in Hong Kong?}

Respondents were asked to rate the level of importance for each of the ten priority areas. Along the 5-year study period, all the 10 priority areas received consistently high ratings of importance of 7 or higher out of 10. Their average scores are given in Fig. 1.

From 2003 to 2007, Education System, Environmental Protection, Health and Hygiene ranked top three most important issues contributing to the sustainable development in Hong Kong. In contrast, Civil Liberties and Human Rights, Integration with the Mainland and Population Policy always ranked the least important issues contributing to sustainable Hong Kong.

Table 1 HKSDI values from 2003 to 2007

\begin{tabular}{lll}
\hline Year & Sample size & $\begin{array}{l}\text { HKSDI } \\
\text { value }\end{array}$ \\
\hline 2007 & 2,021 & 103.7 \\
2006 & 2,054 & 102.2 \\
2005 & 2,051 & 102.5 \\
2004 & 2,515 & 102.8 \\
2003 & 2,501 & 100.0 \\
\hline
\end{tabular}

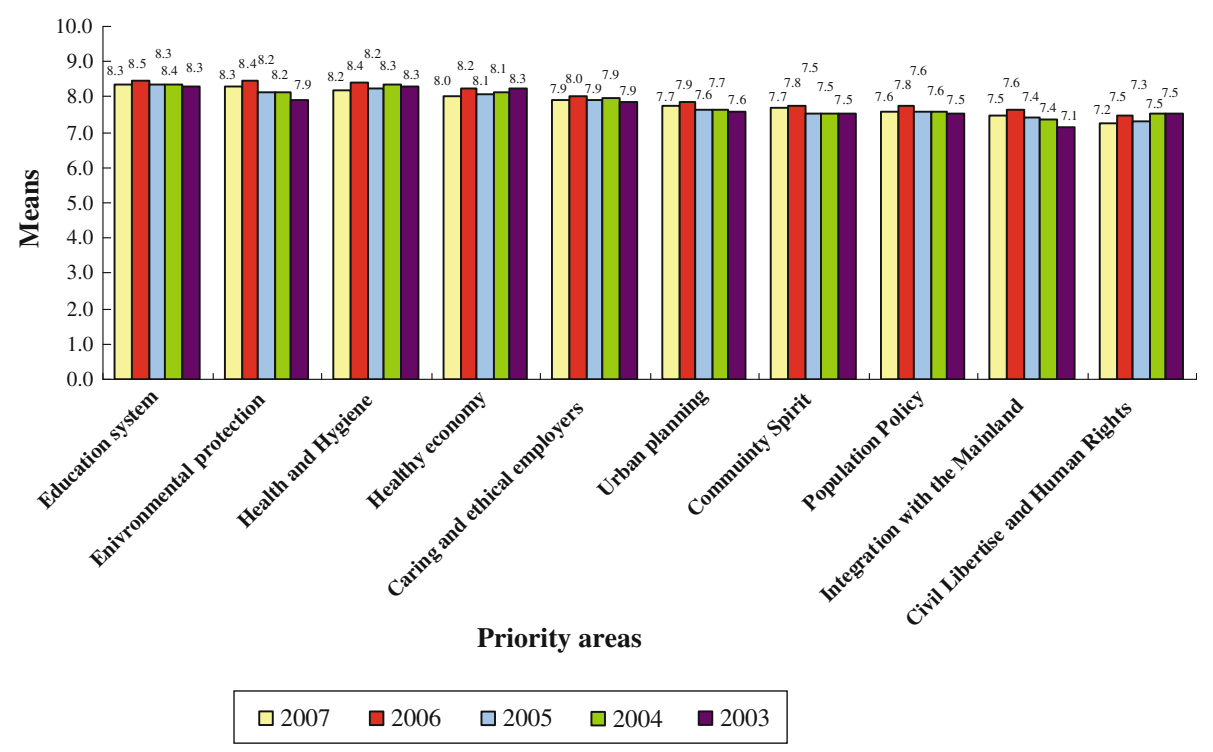

Fig. 1 Annual ranking of results on the importance of each priority area in furthering sustainable development in Hong Kong 
Table 2 Importance trend from 2003 to 2007

\begin{tabular}{llllll}
\hline & 2003 & 2004 & 2005 & 2006 & 2007 \\
\hline $\begin{array}{l}\text { Most } \\
\text { important }\end{array}$ & $\begin{array}{c}\text { Education } \\
\text { System (8.30) }\end{array}$ & $\begin{array}{c}\text { Education } \\
\text { System (8.37) }\end{array}$ & $\begin{array}{c}\text { Education System } \\
(8.34)\end{array}$ & $\begin{array}{c}\text { Education System } \\
(8.48)\end{array}$ & $\begin{array}{c}\text { Education System } \\
\text { (8.34) }\end{array}$ \\
$\begin{array}{c}\text { Least } \\
\text { important }\end{array}$ & $\begin{array}{c}\text { Integration with } \\
\text { the Mainland }\end{array}$ & $\begin{array}{c}\text { Integration with } \\
\text { the Mainland }\end{array}$ & $\begin{array}{c}\text { Civil Liberties } \\
\text { and Human }\end{array}$ & $\begin{array}{c}\text { Civil Liberties } \\
\text { and Human }\end{array}$ & $\begin{array}{c}\text { Civil Liberties } \\
\text { and Human }\end{array}$ \\
& $(7.12)$ & $(7.35)$ & Rights (7.29) & Rights (7.49) & Rights (7.23) \\
\hline
\end{tabular}

To further understand the trends, the "most important" and "least important" areas along the 5 years period are listed in Table 2. It is found that Education System has always been perceived the most important aspect. On the other hand, Integration with the Mainland was initially rated as the least important area, and then it shifted to Civil Liberties and Human Rights. During the growing economy period from 2005 to 2007, it is interesting to note that respondents rated Civil Liberties and Human Rights the least important aspect for sustainable development.

Furthermore, in order to monitor the possible change in the importance ratings of the 10 priority areas along the 5-year study period, a one-way analysis of variance (ANOVA) was conducted. Here the factor refers to the year from 2003 to 2007, and the response variable is the importance rating of each of the priority areas. As resulted from the $F$-test for the overall significance, no significant difference (at 5\% level) in the 5-year period for each of the priority areas has been found.

\subsection{How Satisfied are You With Our Quality of Life?}

Respondents were also asked to rate how satisfied they were with Hong Kong's performance in each of the 10 priority areas that were important to their quality of life. From Fig. 2, except for Healthy Economy that has markedly improved its performance since 2003, satisfaction levels have remained relatively consistent for other priority areas. None of them received an average score of more than 6 out of 10 and the majority average scores were around 5 out of 10 .

Table 3 shows the best and the worst performance priority areas. It is found that Health and Hygiene has continuously been rated as the best performing area. This should relate to the community's general awareness in health and hygiene and the Government's effort in alleviating public health standards, particularly after the SARS outbreak in 2003. On the other hand, Healthy Economy was rated as the worst performing area from 2003 to 2004, and then Population Policy in the following 3 years. This may be caused by the fact that Hong Kong's economy has reached its bottom in 2003 and 2004 since the Asian financial crisis occurred in 1997, and started to pick up slowly from the second half of 2004. When the economy started to rebound, many Hong Kong people switched their attention to the immigration problem from Mainland China, especially because the local news often reported the inflow of pregnant women from the Mainland to give birth in Hong Kong, whereas the birth rate of local residents keeps on decreasing. This may increase the number of people to opine that the Government should perform better in setting up her population policy.

Furthermore, to identify the change in the performance of each priority area along the 5 -year study period, a one-way analysis of variance (ANOVA) was conducted. Here the factor refers to the year from 2003 to 2007, and the response variable is the performance 


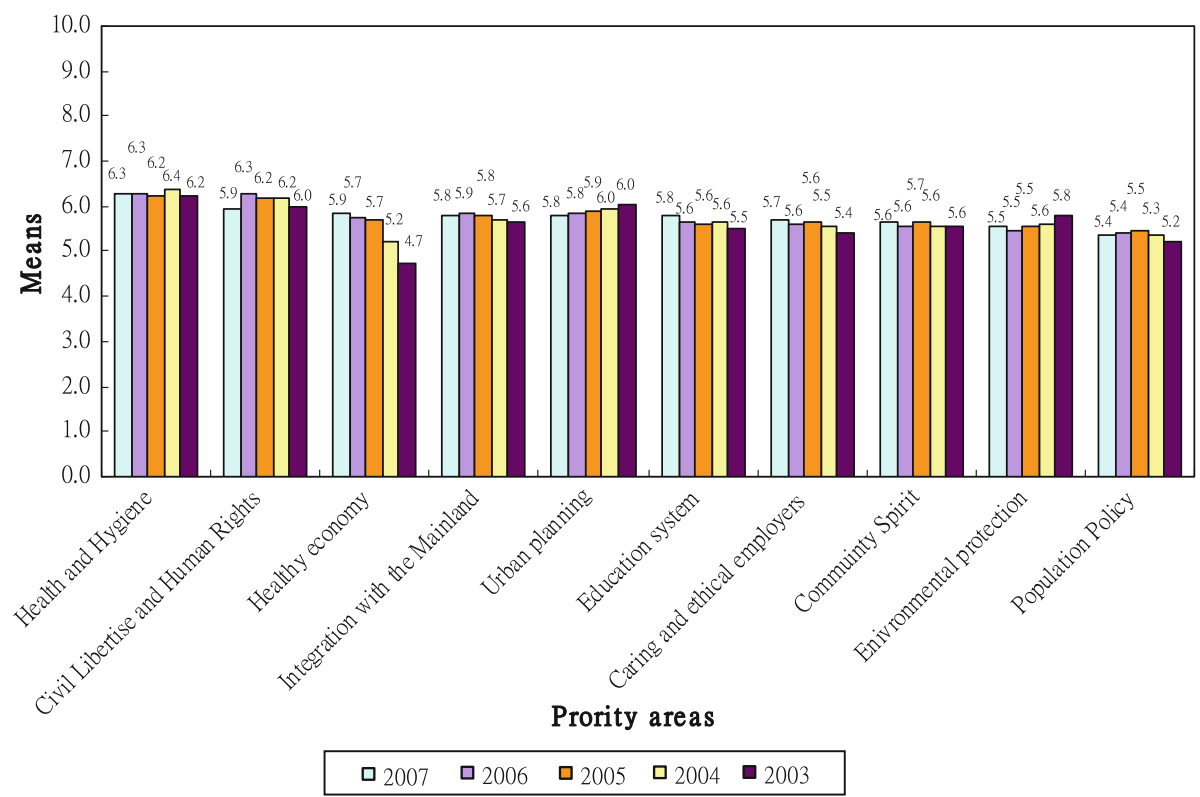

Fig. 2 Annual ranking of results on the performance of each priority area in furthering sustainable development in Hong Kong

Table 3 Performance Trend from 2003 to 2007

\begin{tabular}{|c|c|c|c|c|c|}
\hline & 2003 & 2004 & 2005 & 2006 & 2007 \\
\hline $\begin{array}{l}\text { Best } \\
\text { performance }\end{array}$ & $\begin{array}{l}\text { Health and } \\
\text { hygiene (6.21) }\end{array}$ & $\begin{array}{l}\text { Health and } \\
\text { hygiene (6.37) }\end{array}$ & $\begin{array}{l}\text { Health and } \\
\text { hygiene (6.24) }\end{array}$ & $\begin{array}{l}\text { Health and } \\
\text { hygiene (6.28) }\end{array}$ & $\begin{array}{l}\text { Health and } \\
\text { hygiene (6.30) }\end{array}$ \\
\hline $\begin{array}{l}\text { Worst } \\
\text { performance }\end{array}$ & $\begin{array}{l}\text { Healthy } \\
\text { Economy } \\
(4.73)\end{array}$ & $\begin{array}{l}\text { Healthy } \\
\text { Economy } \\
(5.23)\end{array}$ & $\begin{array}{l}\text { Population } \\
\text { policy }(5.47)\end{array}$ & $\begin{array}{l}\text { Population } \\
\text { policy (5.39) }\end{array}$ & $\begin{array}{l}\text { Population } \\
\text { policy }(5.35)\end{array}$ \\
\hline
\end{tabular}

rating of each priority area. An $F$-test on overall significance revealed significant difference (at 5\% level) in three areas: Healthy Economy, Caring \& Ethical Employer and Environmental Protection. The mean scores and the corresponding groupings according to the post-hoc Tukey procedure for these three areas are given in Table 4. The post-hoc procedure performs pairwise multiple comparisons at 5\% level of significance. It aims to determine which yearly mean score differs from the others. Homogeneous groups of yearly mean scores that are not significantly different from the others, and the corresponding yearly patterns, are identified.

Table $4 \mathrm{a}$, b suggest an increasing trend in performance ratings in Healthy Economy and Caring \& Ethical Employer. To formally test these hypotheses, the regression analysis has been used to test the linear trend. Significant trend coefficients (at 5\% level) are found in Healthy Economy (linear trend: 0.272) and Caring \& Ethical Employers (linear trend: 0.059). This may reflect the rebound of Hong Kong's economy in post-SARS outbreak since 2003, employees also started to have their incomes being increased again. 
Table 4 Homogenous groups of yearly mean scores according to the post-hoc Tukey procedure

\begin{tabular}{|c|c|c|c|}
\hline Year & Group 1 & Group 2 & Group 3 \\
\hline \multicolumn{4}{|c|}{ (a) Priority area: Healthy Economy } \\
\hline 2003 & 4.74 & & \\
\hline 2004 & & 5.26 & \\
\hline 2005 & & & 5.74 \\
\hline 2006 & & & 5.74 \\
\hline 2007 & & & 5.83 \\
\hline \multicolumn{4}{|c|}{ (b) Priority area: caring and ethical employer } \\
\hline 2003 & 5.41 & & \\
\hline 2004 & & 5.56 & \\
\hline 2005 & & 5.60 & \\
\hline 2006 & & 5.67 & \\
\hline 2007 & & 5.69 & \\
\hline \multicolumn{4}{|c|}{ (c) Priority area: environmental protection } \\
\hline 2003 & 5.73 & & \\
\hline 2004 & & 5.44 & \\
\hline 2005 & & 5.53 & \\
\hline 2006 & & 5.53 & \\
\hline 2007 & & 5.55 & \\
\hline
\end{tabular}

\subsection{Importance Versus Performance}

For the 10 priority areas, their corresponding average importance and performance scores along the 5 years period are depicted in Fig. 3. The figures provide a set of descriptive information to schematically present the relative ratings of importance versus performance as perceived by the respondents on the 10 priority areas for sustainable development.

Furthermore, defining Gap = importance-performance, we can compute the approximate performance gap score in each of the 10 priority areas. Table 5 gives the Largest and Smallest Gap results along the 5-year period. Healthy Economy is found to have the largest gap from 2003 to 2004. After experiencing the Asian financial crisis in 1997, its impact continuously affects Hong Kong's economy. The SARS incidence in 2003 further expedited the economy from bottoming out. At that time, a strong voice longing for a Healthy Economy should be anticipated. For the year 2005, the largest gap appears in Education System. This may reflect the society's overall disappointment with the education reform policies that gives rise to confusions and created uncertainties as well as lots of changes at that time. Then, from 2006 to 2007, Environmental Protection shows the largest performance gap because the air pollution problem is getting more obvious and people are demanding to see a clear sky again. On the other hand, the smallest gap is mainly found in Civil Liberties and Human Rights. This may associate with the previous observation that Civil Liberties and Human Rights has been rated as the least important aspect for sustainable development, and that it has relatively high ratings on the performance.

\subsection{Which Aspects Would Improve the Quality of Life in Hong Kong?}

Respondents were also asked in an open-ended question to identify the aspects in each of the 10 priority areas that needed further improvement. This information can help the 

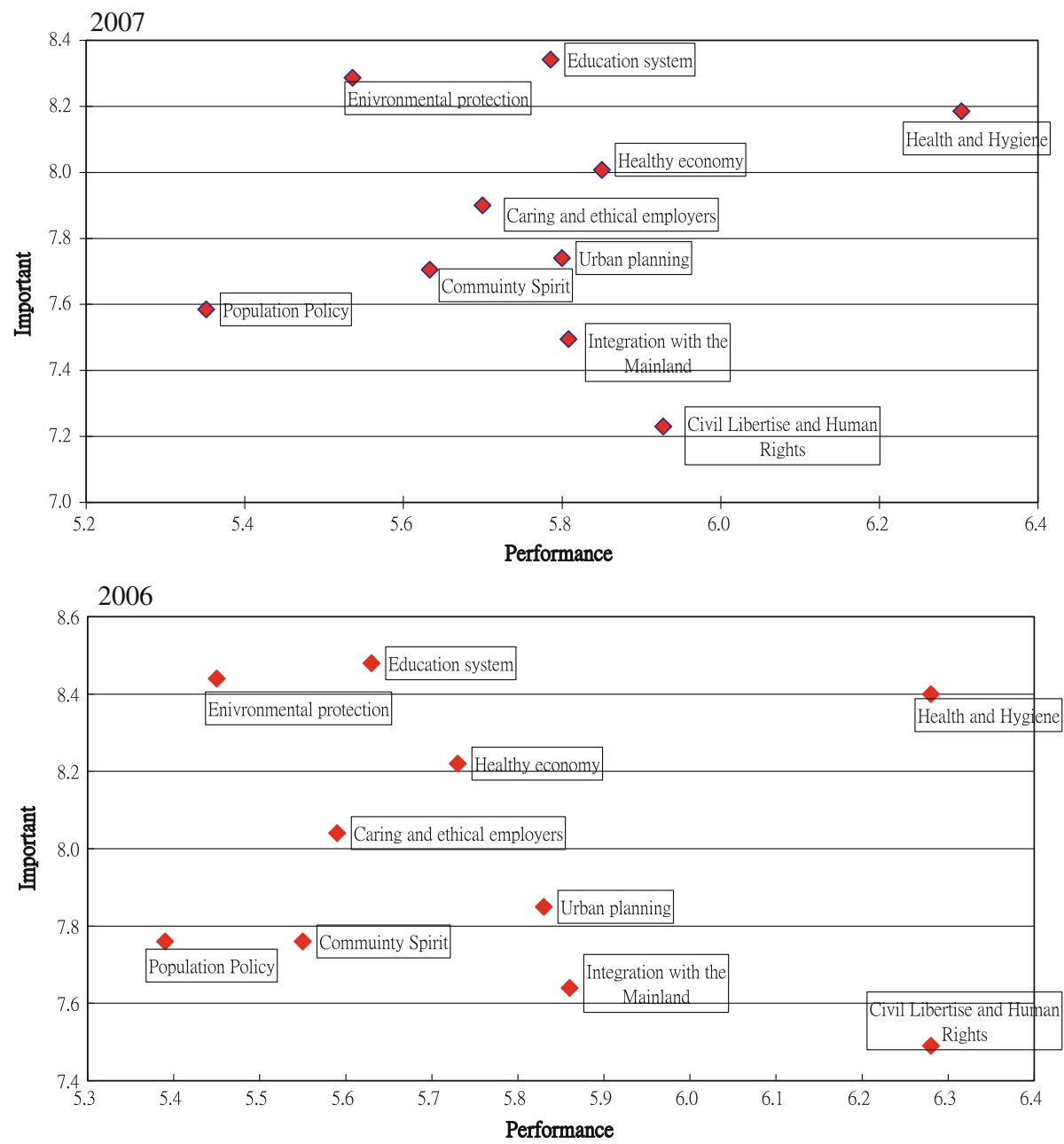

Fig. 3 Importance versus Performance from 2003 to 2007

stakeholders to identify specific aspects that are essential for improving performance in the priority areas, and thus contribute to improve the overall sustainable development. Detailed results are summarized in frequency tables and shown in the annual reports released through the Canadian Chamber of Commerce. As an extract from these results, for the economy, aspects such as creating employment, improving employee benefits, and trade opportunities are most important, whereas reducing air pollution, improving cleanliness of the city and establishing more open and green space are important on the environmental side. On the people side, they demand good teaching quality be found in schools; better immigration policy for Mainland people; higher civic consciousness and care for others; as well as freedom of speech. These demands have not been changed over the past few years. 

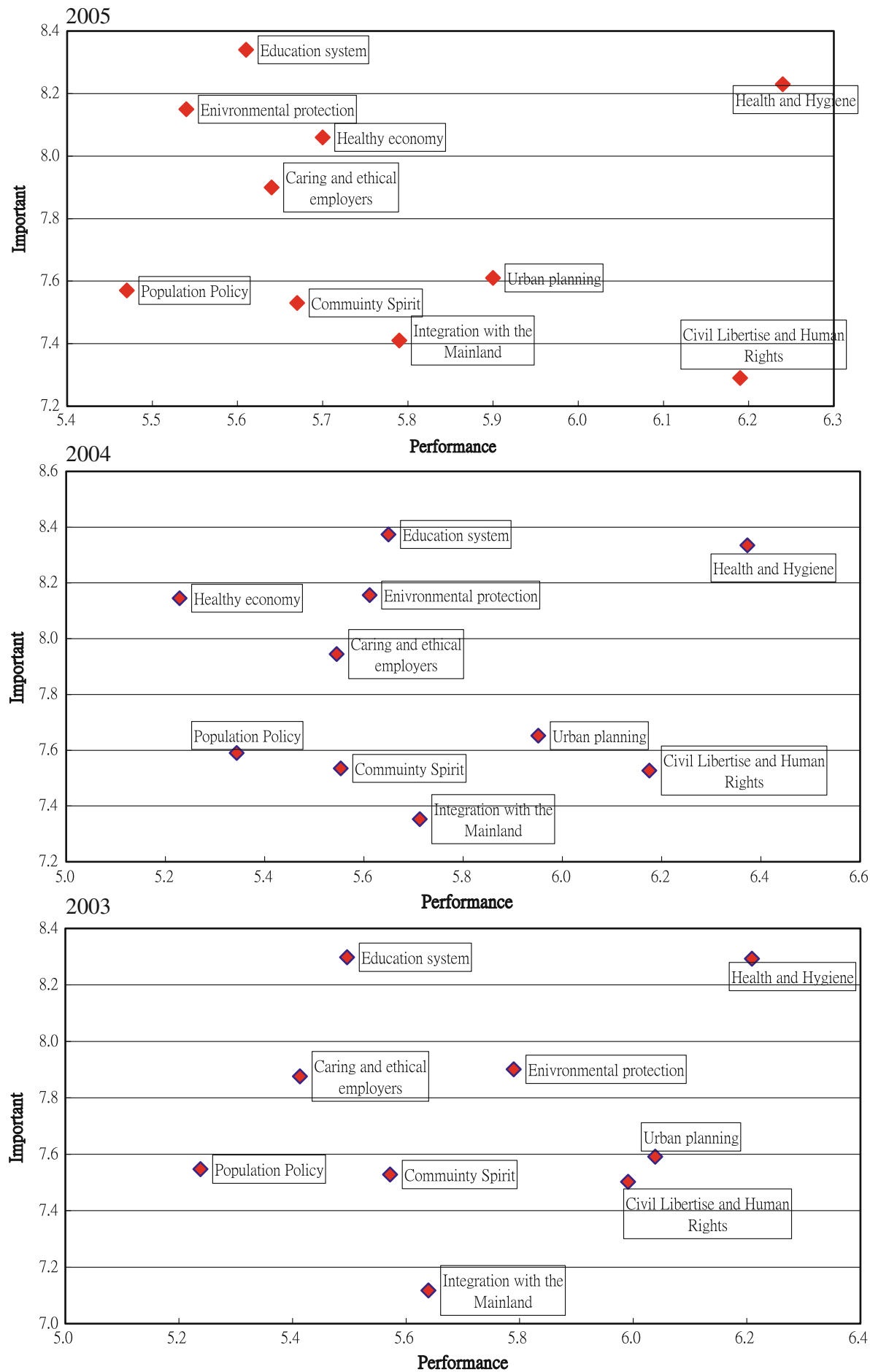

Fig. 3 continued 
Table 5 Gap trend from 2003 to 2007

\begin{tabular}{clllll}
\hline & 2003 & 2004 & 2005 & 2006 & 2007 \\
\hline $\begin{array}{c}\text { Largest } \\
\text { gap }\end{array}$ & $\begin{array}{c}\text { Healthy } \\
\text { Economy }\end{array}$ & $\begin{array}{c}\text { Healthy Economy } \\
(2.92)\end{array}$ & $\begin{array}{c}\text { Education System } \\
(2.73)\end{array}$ & $\begin{array}{c}\text { Environmental } \\
\text { Protection } \\
(2.99)\end{array}$ & $\begin{array}{c}\text { Environmental } \\
\text { Protection } \\
(2.75)\end{array}$ \\
$\begin{array}{c}\text { Smallest } \\
\text { gap }\end{array}$ & $\begin{array}{c}\text { Integration with } \\
\text { the Mainland }\end{array}$ & $\begin{array}{c}\text { Civil Liberties } \\
\text { and Human }\end{array}$ & $\begin{array}{c}\text { Civil Liberties } \\
\text { and Human }\end{array}$ & $\begin{array}{c}\text { Civil Liberties } \\
\text { and Human }\end{array}$ & $\begin{array}{c}\text { Civil Liberties } \\
\text { and Human }\end{array}$ \\
& $(1.48)$ & Rights (1.35) & Rights (1.10) & Rights (1.21) & Rights (1.30) \\
\hline
\end{tabular}

\section{Discussion and Limitations}

According to the findings in Sect. 4, Education System, environmental protection and health and hygiene are the three most important areas in achieving quality of life in Hong Kong. The performance in these areas has great influence on quality of life.

Hong Kong people remained satisfied with the performance of health and hygiene along the 5-year study period. The outbreak of severe acute respiratory syndrome (SARS) in several Asian countries and Canada in 2003 has aroused public concern over health and hygiene. After the SARS crisis, more people have become aware of the importance of the environment to their health. Subsequently, a practical assessment scheme for assessing the health and hygiene performance of apartment buildings in Hong Kong has been developed by Ho et al. (2004). Hong Kong government has put a lot of efforts and resources in this area and more policies have been put forward to prevent the occurrence of disease in various ways. The survey results suggest that these actions are effective. Although currently people are satisfied with the performance on this area, our survey results still indicate that cleanliness of public spaces needs further improvement. The efforts made in this aspect will definitely help people achieve quality of life.

Hong Kong people are also satisfied with the performance of Education System in the past years except 2005 in which the gap of importance and performance in this area is one of the largest. According to the survey, two aspects, namely, quality of teaching and restructuring Hong Kong's Education System, need further improvement to achieve quality of life. In fact, education is a critical issue in changing people's norms, values, interests as well as behaviour. Educational strategy is significant in shaping the culture of the society, which deeply changes the norms of the people and influences individuals' behaviour. The contribution of continuing education and leadership empowerment to sustainable development has been investigated by Wong (2003).

Environmental protection is one of the most important areas to achieve quality of life. However, the performance in this area is not satisfied comparing to others, especially after 2003. The results of ANOVA (Table 4c) show that there is a significant difference concerning the performance between 2003 and the years after. According to the survey results, along the 5-year study period air quality is consistently identified as the major aspect which needs to be further improved. In fact, Hong Kong's long-persisted air pollution problem has been internationally recognized. As early as 1966, the government set up a committee to study air pollution generated by the industrial activities and motor vehicles. Despite historical concerns, air quality deteriorated markedly in the 1990s. As reported by the Hong Kong Environment Protection Department in 2002, the increase in the number of poor-visibility days raised public awareness of the problem. In particular, Hills (2002) discussed the evolution of environmental policy in Hong Kong and a regional 
environmental management agenda. Our survey results also indicated that people worried about air pollution and were eager to improve air cleanliness. In fact, air pollution has been known to be a significant risk factor associating with the increased mortality rate due to all respiratory diseases, influenza and cardiovascular diseases. The recent crisis in air quality comes at a crossroads in Hong Kong history. Following its return to China in 1997, Hong Kong has been struggling to retain its status as a world-class city and the financial capital of East Asia. In the fight to maintain a competitive edge, air quality has taken on increased importance. Therefore, whether Hong Kong government and business industries can jointly work on this problem effectively is very important to retain and reinforce the competitiveness of Hong Kong in global economy as well as achieve quality of life.

Besides, according to the ANOVA results on the possible change in performance ratings, we found that the area of Healthy Economy has been improved continuously. The success experience of achieving improvement in this priority area could be summarized and used as a reference in other areas. Alternatively, the performance on population policy was the worst during 2005-2007. In particular, managing immigration from the mainland China is the major aspect which needs further improvement. Law and Lee (2006) investigated the relationship between citizenship, economy and social exclusion of mainland Chinese immigrants in Hong Kong. Three interrelated dimensions of the social exclusion of Chinese migrants in Hong Kong: (1) globalisation; (2) political attempts of territorial states; (3) nature and strength of local place-based social identity, were discussed. Hong Kong is often viewed as a society of Chinese immigrants. Hong Kong's immigration control regime has changed in accordance with the development of the economy. Different regime was applied in different historical periods, such as Touch-Base Policy in 1980, One-Way Permit, Two-Way Permit, General Labour Importation Scheme, Admission of Talents Scheme, etc. On one hand, these policies were helpful to economic development in Hong Kong by providing labour resources during a certain period of time. But on the other hand, it also created a lot of problems at the same time. The newcomers were sometimes seen as aggravating the territory's social problems by increasing competition for jobs, houses, and welfare benefits. After the Asian Financial Crisis in 1997, Hong Kong's economic recession deepened. Hong Kong people's negative perception towards new arrivals further intensified. Looking ahead, to reinforce Hong Kong's high-tech and high value-added industrial development strategy, an appropriate population policy is needed. Given the keen competition among global cities, the government should more actively seek mainland Chinese talents that might help transform the economy into a knowledge-based metropolis in order to enhance the competitive status of Hong Kong. As such, it is essential to have a flexible immigration policy to attract mainland Chinese talents to root in Hong Kong.

In general, many aspects should be considered in order to achieve a better quality of life. As pointed out by Chua et al. (2010), social and economic developments are equally important and inter-connected. Excessive focus on any one aspect is harmful to the development of the society. Assigning appropriate importance weights to the social, economic, cultural and environmental development, which are the four cornerstones for integrated and balanced social development, is deemed crucial.

There are some limitations in this study. Firstly, the response rate in this study is not very high due to the resources we can afford on the interviewing cost and the length of the questionnaire. Ideally a good telephone survey requires a high response rate. However, resources on interviewing cost and time will be needed in order to increase the response rate in any telephone survey. Secondly, although each respondent has provided a rating on his/her importance and satisfaction levels towards each of the priority areas, they may in 
fact refer to different specific aspects in that area. Nevertheless, this problem is unavoidable in practice because individuals may have their own concerns in each of these priority areas.

Acknowledgments The authors would like to thank the reviewer for constructive and helpful comments. The development of HKSDI is a joint project conducted by the Canadian Chamber of Commerce in Hong Kong and the City University of Hong Kong. The authors would like to thank the Canadian Chamber of Commerce for providing the financial sponsorship on data collection and valuable advice on the interpretation of results. The project is partially sponsored by the Scientific Research Foundation for the Returned Overseas Chinese Scholars, State Education Ministry, P. R. China.

\section{References}

Barrios, E., \& Komoto, K. (2006). Some approaches to the construction of a sustainable development index for the Philippines. International Journal of Sustainable Development and World Ecology, 13, 277288.

Chiu, L. H. (2000). Environmental sustainability of Hong Kong's housing system and housing process model. International Planning Studies, 5(1), 45-64.

Chiu, L. H. (2002). Social equity in housing in the Hong Kong special administrative region: A social sustainability perspective. Sustainable Development, 10, 155-162.

Chua, H. W., Wong, A. K. W., \& Shek, D. T. L. (2010). Social Development in Hong Kong: Development issues identified by Social Development Index (SDI). Social Indicators Research, 95, 535-551.

Daly, H. E., \& Cobb, J. B, Jr. (1989). For the common good. Boston: Beacon Press.

Herrera-Ulloa, A. F., Charles, A. T., Lluch-Cota, S. E., Ramirez-Aguirre, H., Hernandez-Vazquez, S., \& Ortega-Rubio, A. F. (2003). A regional-scale sustainable development index: The case of Baja California Sur, Mexico. International Journal of Sustainable Development and World Ecology, 10, 353360 .

Hills, P. (2002). Environmental policy and planning in Hong Kong: An emerging regional agenda. Sustainable Development, 10, 171-178.

Ho, D. C. W., Leung, H. F., Wong, S. K., Cheung, A. K. C., Lau, S. S. Y., Wong, W. S., et al. (2004). Assessing the health and hygiene performance of apartment buildings. Facilities, 22, 58-69.

Hoballah, A. (2006). Sustainable development in the Mediterranean region. Natural Resources Forum, 30(2), 157-167.

Hoffman, J. (2000). The roots index: Exploring indices as measures of local sustainable development, New York City: 1990-95. Social Indicators Research, 52(2), 95-134.

Kizilaslan, N., Gurler, A. Z., \& Kizilaslan, H. (2007). An analytical approach to sustainable development in Turkey. Sustainable Development, 15(4), 254-266.

Lai, W. C., Chau, K. W., Ho, C. W., \& Lorne, T. (2006). A "Hong Kong" model of sustainable development. Property Management, 24(3), 251-271.

Law, K. Y., \& Lee, K. M. (2006). Citizenship, economy and social exclusion of mainland Chinese immigrants in Hong Kong. Journal of Contemporary Asia, 36, 217-242.

Lawn, P. A. (2003). A theoretical foundation to support the index of sustainable economic welfare (ISEW), Genuine progress indicator (GPI), and other related indexes. Ecological Economics, 44(1), 105-118.

Ledoux, L., Mertens, R., \& Wolff, P. (2005). EU sustainable development indicators: An overview. Natural Resources Forum, 29(4), 392-403.

Lu, W. M., \& Lo, S. F. (2007). A benchmark-learning roadmap for regional sustainable development in China. The Journal of the Operational Research Society, 58(7), 841-849.

Luken, R. A., \& Hesp, P. (2007). The contribution of six developing countries' industry to sustainable development. Sustainable Development, 15(4), 242-253.

Munday, M., \& Roberts, A. (2006). Developing approaches to measuring and monitoring sustainable development in Wales: A review. Regional Studies, 40(5), 535-554.

Ng, M. K. (2007). Sustainable development and governance in East Asian World Cities. Journal of Comparative Policy Analysis, 9(4), 321-336.

Nordhaus, W. D., \& Tobin, J. (1973). Is growth obsolete. Studies in Income and Wealth, 38, 509-532.

Roberts, P. (2006). Evaluating regional sustainable development: Approaches, methods and the politics of analysis. Journal of Environmental Planning and Management, 49(4), 515-532. 
Roberts, P., \& Hills, P. (2002). Sustainable development: Analysis and policy in east and west-the cases of Hong Kong and Scotland. Sustainable Development, 10, 117-121.

Shek, D. T. L. (2010). Introduction: Quality of life of Chinese people in a changing world. Social Indicators Research, 95, 357-361.

Short, T. (2008). Sustainable development in Rwanda: Industry and government. Sustainable Development, 16(1), 56-69.

Tarabusi, E. C., \& Palazzi, P. (2004). An index for sustainable development. Banca Nazionale del Lavoro Quarterly Review, 57(229), 185-206.

Wong, O. W. (2003). Analysing the contribution of continuing education and leadership empowerment to sustainable development. International Journal of Sustainability in Higher Education, 4, 364-374.

Zavadskas, E. K., Kaklauskas, A., \& Kaklauskiene, J. (2007). Modelling and forecasting of a rational and sustainable development of Vilnius: Emphasis on pollution. International Journal of Environment and Pollution, 30(3/4), 485-500. 